\title{
Architectural Competitions. Architecture as Essay
}

\author{
LUIS PANCORBO \\ University of Virginia
}

\section{INTRODUCTION}

Creation offers itself for definition as that which is enacted freedom, and which includes and expresses in its incarnation the presence of what is absent from it or of what could be radically other. ${ }^{1}$

\section{-George Steiner, Grammars of Creation}

When we considered writing this paper, we deliberately opted for a reflexive mode of reasoning. Reflection has two clear meanings for us; on the one hand, reflection refers to a type of thinking that excludes the definite search for a purpose and a rigid prior method. On the other hand, it is a strategic activity. The ductility of its structure allows changing objectives, tactics and techniques used according to the answers and difficulties encountered through process itself. The flexibility of structure, of course, implies its existence. The usefulness of this method, its great ability to open previous data fields and suggest different ways and interpretations, is enhanced if it manages to fuse all this as facets of the same polyhedron.

On the other hand, etymologically reflection is not only rumination, but it is also a "mirror," a returned image from our own actions. As Viktor Shklovsky relates in his rewriting of the centipede fable, looking at one's legs is always a dangerous exercise. When facing the analysis and schematization of the design process of a complex iterative decision-making system, there is a risk of blocking it due to lack of automation and excessive rationalization. Hence we proceed with caution, focusing on only of a part of the complex synchronized movement of our hundred legs. We then posit that there is no better point of focus than the very start of motion, the initial step in the first instant that triggers all subsequent development.

\section{START AND LOSS}

Italo Calvino tells us that a beginning is based on the deviation from the infinite potentiality, ${ }^{2}$ for by means of decision-making, we access to the world of concretion. We also know that in this dramatic act we lose the potentiality of being another thing. George Steiner argues that in literature the first step can never be free of pollution from empirical or polysemic constructions. The same thing happens in an architectural project. Architecture is an activity that does not support the abstract purity of music

\author{
INES MARTIN ROBLES \\ University of Virginia
}

or mathematics, which have formal autonomy, based on autonomous generative structures. Architecture, like literature, is impure and realistic, dependent on innumerable influences: the available materials and techniques, the program, the place, etc. Furthermore, architecture only makes sense with its materialization, what Gilbert Simondon ${ }^{3}$ might call its "individuation." Literature and architecture express themselves in a language established in its time, with a certain syntax and lexicon determined by the current context. Hence, the personal search in architecture, the search for originality, always becomes a grotesque idiolect or a clumsy involuntary plagiarism.

This natural tendency of Architecture toward concretion, toward the elimination of all potentiality, although it is part of its essence, can be nuanced in this analysis of its first steps. After a long experience carrying out projects and especially architectural competitions, we have glimpsed the following paradox.

Architectural projects and competition entries- to an even greater extent due to their tentative character- never exist as finished objects. Whether manifest or encrypted, they always contain previous versions of themselves. This paradoxical situation is similar to one explained by Steiner:

Drafts, canceled versions, worksheets, internalize what Leibniz termed 'the great mystery of that which could have been', in both negative and positive senses. ${ }^{4}$

\section{WALKING BETWEEN TWO ABYSS.}

All those who devote themselves to design practice in general and particularly to the realization of competitions will identify with the fear this first line invokes, a fear or anxiety that to fix those first concepts supposes discarding infinite possibilities perhaps more valid and successful than the one which will actually be developed. It is a feeling similar to vertigo on approaching an abyss. To understand this vertigo, we turn to Blaise Pascal, who in "Pensees" explains:

For, in fact, what is man in nature? A Nothing in comparison with the Infinite, an All in comparison with the Nothing, a mean between nothing and everything. Since he is infinitely removed from comprehending the extremes, the end of things and their beginning are hopelessly hidden from him in an impenetrable secret; he is equally incapable of seeing the Nothing from which he was made, and the Infinite in which he is swallowed 


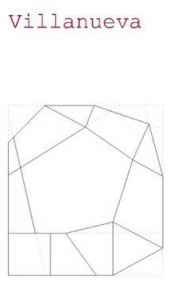

geometric generation

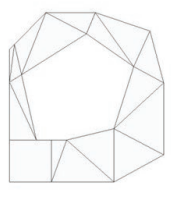

structure generation

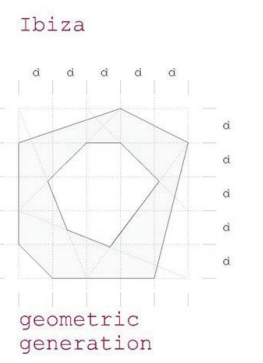

geometric generation

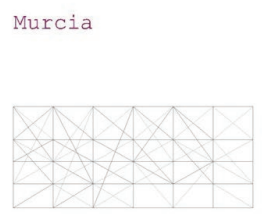

01 geometry

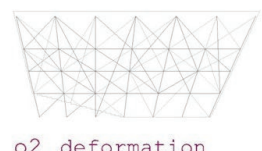

02 deformation

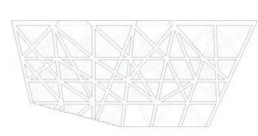

03 structure

Figure 1. Comparative geometrical generation of 3 competitions.

up (...) If we are well informed, we understand that, as nature has graven her image and that of her Author on all things, they almost all partake of her double infinity. ${ }^{5}$

Similarly, as Pascal believes in the abysses of the infinitely large and the infinitely small, we believe that architectural project produces the vertigo of approaching complete concretion and endless potentiality. Is there any way to alleviate that fear of the beginning, of the annihilation of potentiality? Once again, Steiner shows us the way:

The internalization within the finished work, where "finished" is perhaps the antithesis to "complete," of preceding, alternative, discarded performative solutions, can be made out, as we saw in drafts, in sketches, in the sequence of preliminary maquettes. The ultimate source, together with the ice-berg mass of hidden labor, of trial and error, is, at the outset, sub-liminal. ${ }^{6}$

Thus, each competition submission constitutes part of a constant flow. In these they are present, veiled, explicit, omitted, corrected, modified, recreated or repeated, findings and lessons learned in previous attempts. The discarded versions are also present in each elective bifurcation, each decision made during the project. It could be said that all competitions, no matter how different their outcomes, become part of a single "meta-competition" that covers the entire period of our professional activity.

This thought partly alleviates the fear of beginnings, since a competition proposal is not an absolute beginning, but a partial one that can be always resumed and reconsidered as many times as necessary. Nevertheless, for this consideration to have value, it is necessary to pay special attention that this beginning does not close into a concrete and unique objective, but leaves open the possibility of varied alternative routes during the design process.

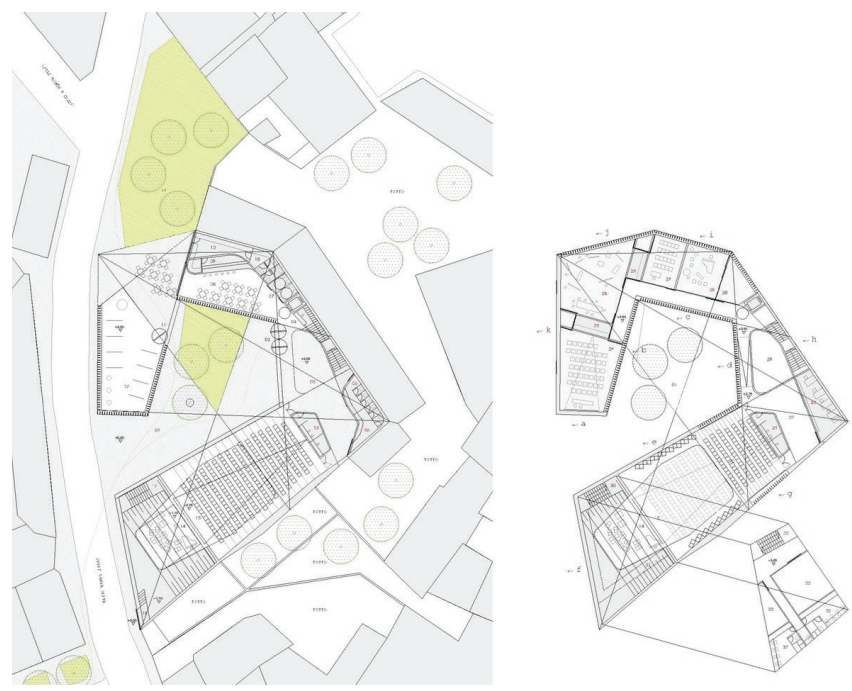

Figure 2. Competition. Cultural Center Cabezon de Pisuerga, Spain.

\section{STRATEGY AND TACTICS.}

In his analysis of the production process of Yeats's poems, Curtis B. Bradford offers the initial seed of the author's "Lullaby," a column of five words:

\section{Sleep, Alarms, Deep, Bed, Arms.}

The poem develops from this nucleus of potentiality to reach several "finished" forms in various publications over time. In all of them, this initial structure is still present; sometimes in a veiled form and sometimes more explicitly. Other times it may be omitted but has a suggested presence. It is only after the initial strategy has been proposed, that the poem is brought closer to concretion and Yeats achieves his "own poetic style" through operations that could be called tactical or programmatic. These tactical movements in Yeats changed according to different times and could be summarized in the counterpoising of classical heritage and Celtic tradition, the exploration of bucolic naturalism, and the use of the dramatic ritualism of Japanese theater. ${ }^{7}$

The strategic framework of the poet is both conceptual and formal; the strategic framework of the architect, as corresponds to a non-significant matter such as architecture, ${ }^{8}$ must necessarily be exclusively conceptual. Any form adopted a priori, any formal characteristic, any adjective can only be used instrumentally in the tactical phase of a project, never in its beginning. If we are allowed a lexicon borrowed from linguistics, in this initial phase it is verbalized and in the conclusive phase, it is substantivized.

That is the strategic structure of Yeats; strategy does not compromise potential, it is a neutral and flexible frame of guiding lines. The program or tactic, based on automatisms, serves to specify and fix. With strategy, the project remains at a tentative level, at the level of the model, the prototype, the unverified scientific hypothesis, or the essay. As Edgar Morin says: 


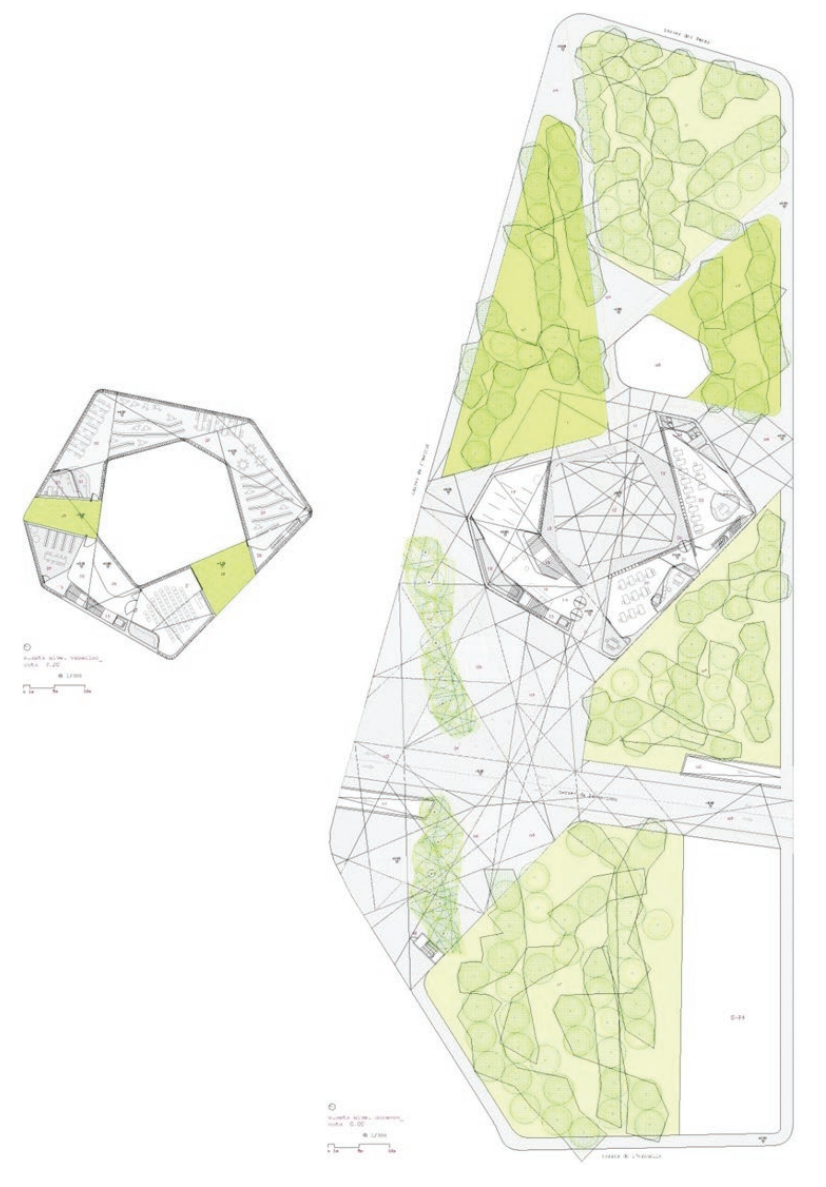

Figure 3. Competition. Cultural Center Santa Eulalia del Rio, Ibiza, Spain.

A program is constituted by a pre-established sequence of actions that are linked together and triggered by a given sign or signal. Strategy is constructed in the course of the action, modifying, according to the emergence of the events or the reception of the information, the behavior of the action considered. Strategy supposes then: a) the aptitude to undertake or to look for in the uncertainty taking into account that uncertainty, b) the aptitude to modify the development of the action in function of the alea and of the new thing. The strategy supposes the aptitude of the subject to use for the action, the exterior determinisms and aleas, and can be defined as the method of action of a subject in a game situation (in the neumannian sense of the term) in which, to achieve its aims, strives to experiment to the minimum and make the most of the constraints, uncertainties and hazards of this game. The program is predetermined in its operations and in that sense it is automatic; the strategy is predetermined in its purposes, but not in
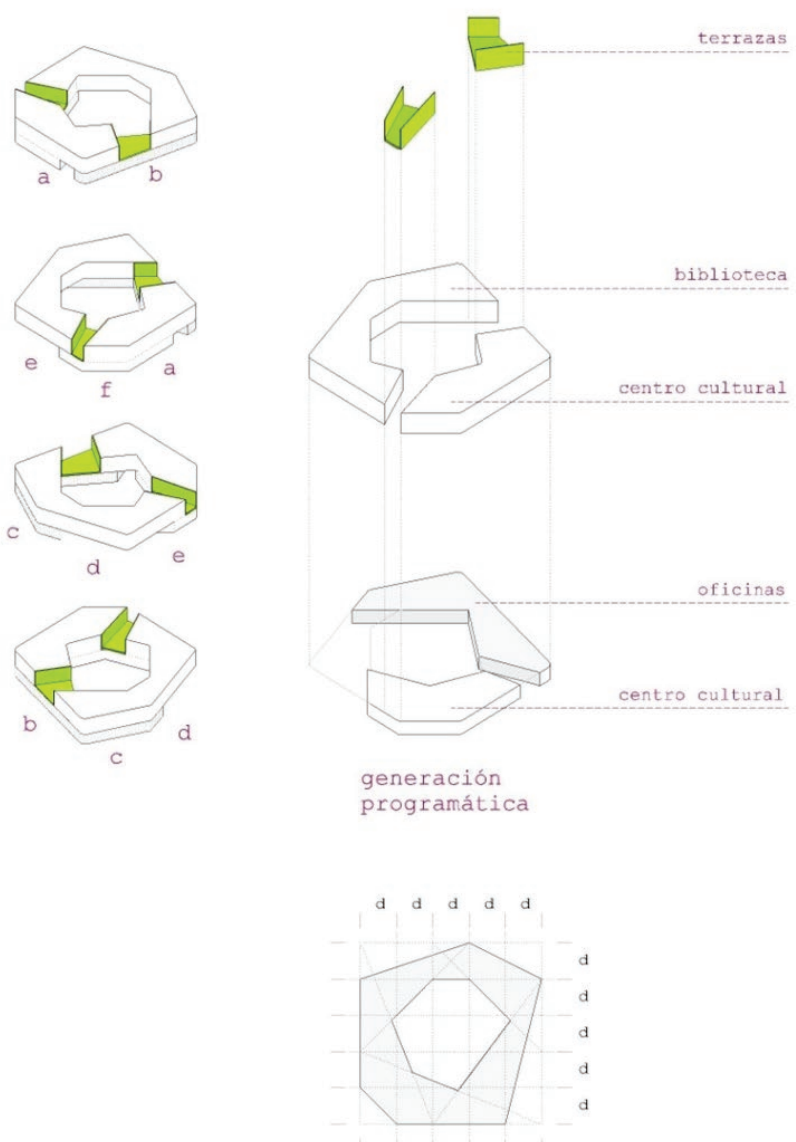

all its operations; In fact, the strategy finds it useful to have very numerous automatisms (programmed sequences) (...) A high strategy cannot find more than advantages with the possibility of triggering, according to the needs, automatisms that it controls. The strategy that is deployed at the global and higher levels then uses the automatism and the program at the lower and segmental levels. ${ }^{9}$

Thus, there would be two ways to start a project. The first is through programmatic operations, more automatic and digital, based on quantification and is useful especially in situations which it is not necessary and perhaps not advisable to undertake any experimentation. Here we use the term experimentation in the sense defined by John Cage:

The term "experimental" is valid as long as it is understood not as the description of an act that will then be judged in terms of success or failure, but simply as an act whose outcome is unknown. ${ }^{10}$ 


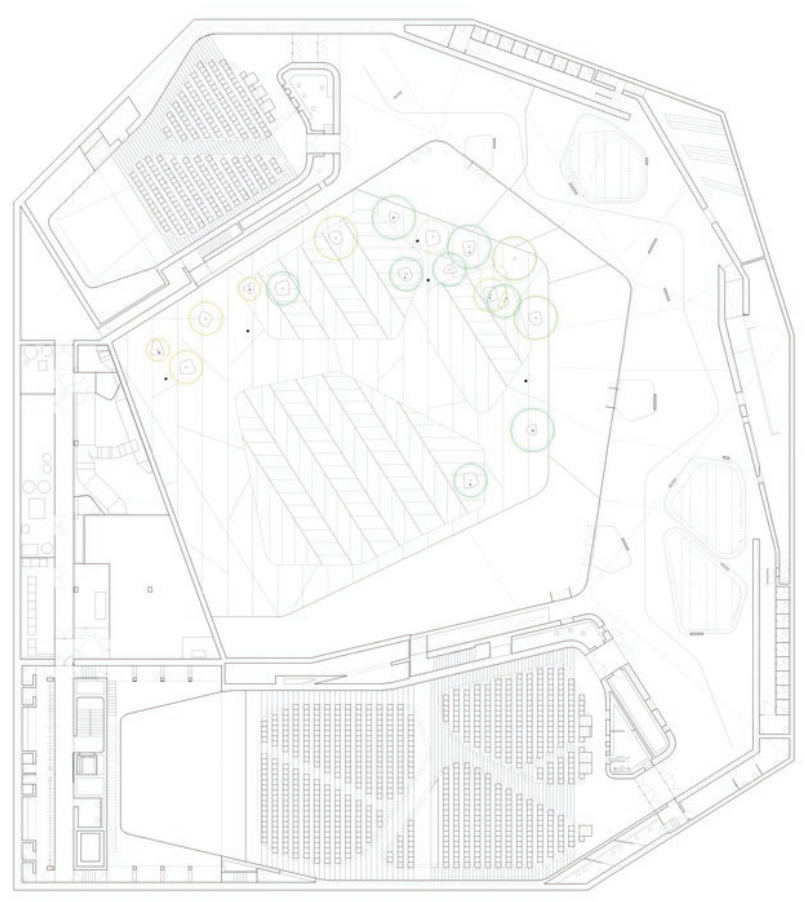

Figure 4. Villanueva de la Serena Congress Center. Floor Plan.

The second form, the analogic, is based on qualification, which we believe is inextricably linked to the architectural competition. It is that which uses strategic operations for its genesis. It is an experimental activity in its conception, both proactive and tentative, and without the constriction of the search for a definite result. It is the way of designing that we call architecture as essay.

This definition applied to the architectural project is given both by the relevance of the word itself to our case of study, the architectural competition, by means of its association with concepts such as sketch, intent, draft, tentative, rehearsal, ${ }^{11}$ and by its proximity to the concept of essay as a literary genre developed specifically by the Spanish philosopher Gustavo Bueno.

It is in the analogic form that we believe that the potentiality "of that which could have been" is maintained; competitions carried out, and most importantly those lost or failed, are steps in a sequence which is not specified by being. All these errors, like previous steps, are ever present in any developed or constructed project, which is nothing more than frozen or paralyzed state of these evolutionary project vectors and architectural research paths.

In this design activity, it is precisely the error verified in the "essay" (trial, rehearsal), which makes us move forward in pursuit of an indefinite objective, along a changing path that adapts to the various situations discovered through process itself. Despite this, we believe that architecture understood as an essay, assuming the implicit concept of "intent," should always allow the substantivity and architectural individuation

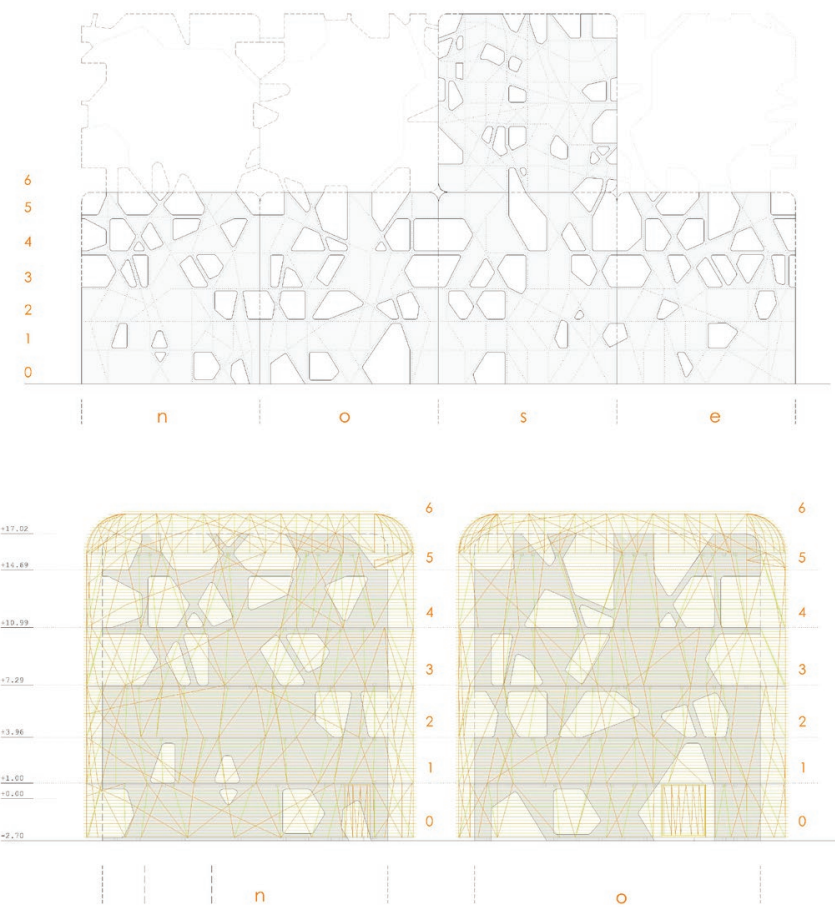

Figure 5. Villanueva de la Serena Congress Center. Elevations.

of the obtained outcome. The competition proposal must look like final and individual. It must not look like it is subordinated to new potential developments and subsequent research

\section{ARCHITECTURE AS ESSAY.}

According to Gustavo Bueno, the essay constitutes a "resumption of the theoretical threads around an event, fertile enough so that different theories can cross within it."12

A project and of course an architectural competition, always start from a fact, a concrete need, a problem to solve expressed through programmatic uses outlined with greater or lesser precision. At this moment is when the differentiation between the programmatic and strategic approach begins.

While programmatic procedure starts from the assumption and meticulous dissection of these constraints, strategic operations must always arise from a new foundation of those considerations, from questioning and subsequent reformulation in a more open and flexible structure. Sometimes constraints become more complex conceptually to allow mutability when confronted with the unforeseen situations that will arise in the process and accommodate the interference and analogical interaction of several categorical spheres (intra or extra-disciplinary). Again Steiner serves as a helpful reference:

In creation, and this may indeed be a cardinal difference from invention, solutions are beggars compared to the riches of the problem. ${ }^{13}$ 


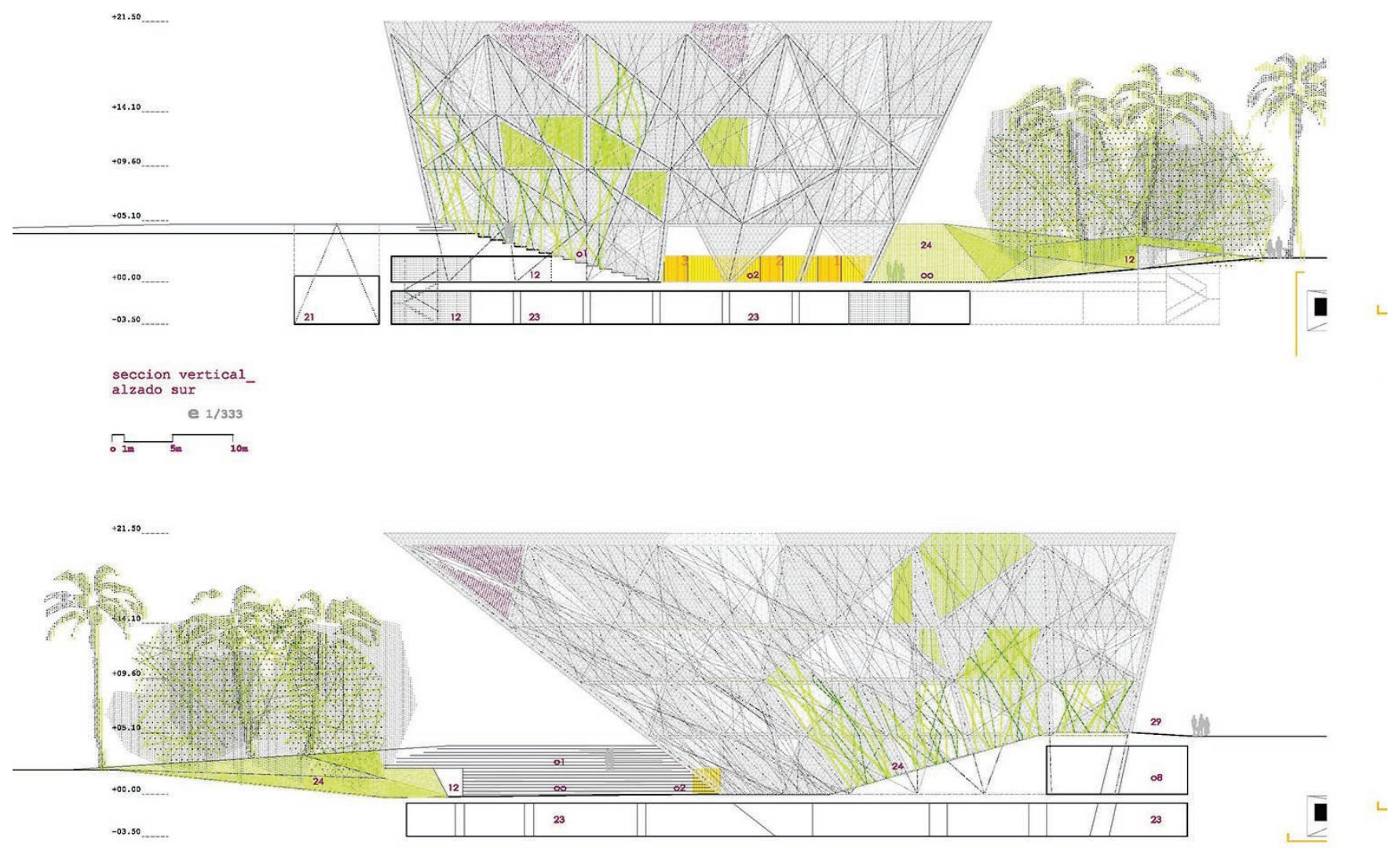

Figure 6. Competition Auditorium Torres de Cotillas, Murcia, Spain.

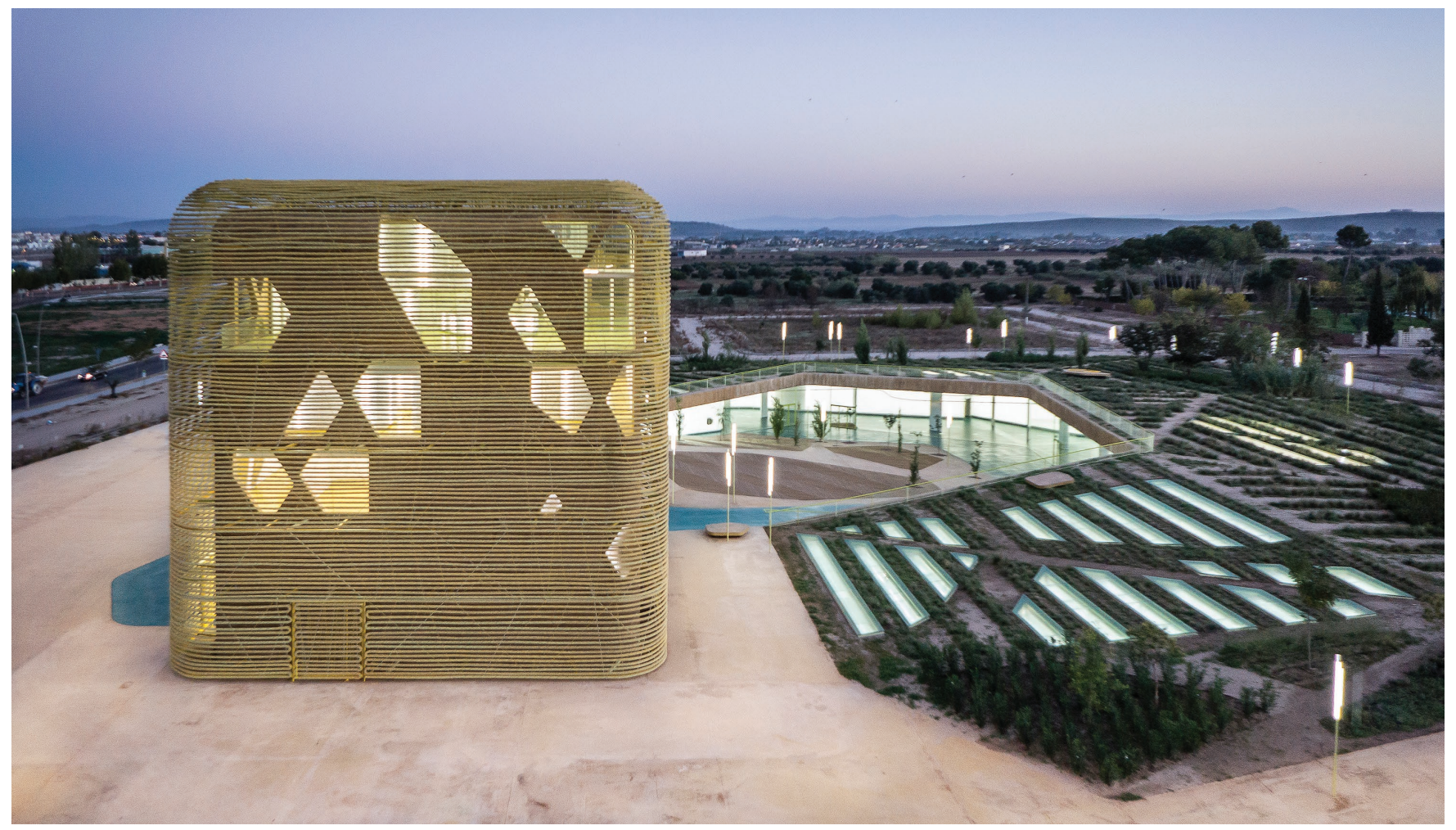

Figure 7. Villanueva de la Serena Congress Center. Photo. Jesus Granada Fotografia. 
We thus approach the vision of the architecture project as a solution to a problem. Of course, it is not necessary to remind anybody that the solution to a problem is always found, it is never known apriori, otherwise, the problem would not be such. In the case of architecture, we must also remember that there is no single solution and given the large number of compounding variables, the statement of a solution is not clearly and precisely known. Hence, there is no rigid and linearly structured project method. The competition (and the architectural project in its most complete version) is an activity that necessarily implies an investigation, a research, a reflection, in short, it is an essay.

According to Gustavo Bueno in his text "On the Concept of Essay," an essay is a construction that is based on the interference of several categorical spheres around a fact, a problem, sufficiently fertile so that different theories can cross it. It is a construction that does not admit by its structure the demonstration, which lacks proof. As José Ortega y Gasset posed, "essay is science without explicit proof." ${ }^{14}$ Quoting Gustavo Bueno again:

Essay does not seek demonstration, but it does not, therefore, offer arbitrary ideas. It theorizes. It tries to form an opinion, reasoning, above all according to analogy. It does not follow the scientific order, but rather the order of things, of the things articulated in the human practical space (...) Analogy (understood as an analogy between different categorical spheres) is the specific procedure of the essay and, I would almost say, its constitutive procedure. We would say that, when a writer has managed to gather several accurate analogies, he or she already has the material for a good essay. This same characteristic can serve as a criterion to measure the quality of an essayist, according to the strength of its analogies. ${ }^{15}$

Reflecting then on the analogy, as the dictionaries define it, ${ }^{16}$ a relation of similarity between different things or reasons based on the existence of similar attributes in those different beings or things, one could also think of the inverse operation, what Viktor Shklovsky called the dissimilarity of the similar. ${ }^{17}$ That is, finding differentiating features in what seems analogous. This is the procedure though which we are able to create an identity for each architectural proposal without losing sight of the notion of the architectural project as a system or flow which is always one even as it is renewed and made different.

Another characteristic identified by Gustavo Bueno as a constituent element of the essay is that it is written in a "national language." It may seem obvious or tautological, but this refers to the fact that essays are not written in a technical language belonging to any specific branch of scientific or technical knowledge, with a peculiar semantics and logical syntax. The language of an essay does not deviate from the syntax and semantics that connect with the original linguistic awareness of a given society.
The blueprints of an architectural project are instructions documents, commands written by and for experts. They are a clear example of language, of a graphic formant and technical in nature. We are reminded of this fact when we see the stupor and incomprehension with which anyone who does not speak this language approaches these documents. On the other hand, the documents created for an architectural competition have a different character; they are not commands. They base their power of transmitting information on a more ambiguous concept, that of suggestion. They are not interfaces between experts, but mediate between expert deliverers and an undefined receptor, an often unknown audience, typically unaware of the language of architecture. It is therefore necessary to use a national language, with an explanatory and promotional voice, that everyone can understand. We would push this further, a competition must use a language of suggestion that allows its audience to gather and complete diffused information in a personal way. It must use a language, which enables each participant to imagines the proposal as "he or she would like it to be." In short, a competition must deliver incomplete, ductile and interpretable documentation. To illustrate this capacity for re-reading, and re-interpretation, we refer again to inexhaustible wealth of G. Steiner:

The errors inevitable of our response, the misunderstandings unavoidable of our interpretative archaeology of feeling, invest in the work its novelty, its intemporality (...) Loss makes new. The original message has been silenced. Or it becomes a retrospective convention, a mythology of meaning. This allows, indeed necessitates the fertile misprisions of renovating response. ${ }^{18}$

Therefore, as a final recapitulation, we can say that starting an architecture competition supposes first of all that one must fix a strategy which rewrites the statement of the problem posed within a practical space, making it complex enough to allow the interweaving of several theoretical threads. Threads of several existent or created ex-novo theories that connected by means of the analogy are developed through tactical actions in an open and tentative way that allow establishing connections with the rest of the real world. The competition documents will also be "written" (read and drawn) in a language that admits the possibility of re-reading and re-interpreting by those who will serve as the jury. They also must allow the author to re-use the submitted proposal in later productions, becoming part of an organic flow.

As in any essay, our intention is not to exhaust the subject (which is, after all, inexhaustible), but to sketch and open it to other possible developments. We would like to fray it so that others pull at the "fringes." We characterize architecture as essay in invitation of a multitude of viewpoints. From the search for answers to questions that arise when rereading this text we envision others may raise a multiplicity of questions: Is the use of citations in an essay comparable 
to the references used in an architectural project? Is this use analogous to the use of typology as a design tool? What are the roles of personal memory and the arbitrary or premeditated selection that this use entails for the project and for the essay? Does there exist a personal frame of reference or point of view in architectural design? Could the previous questions be related to the use of tools such as collage, montage, and post-production? What is the role of personal authorship? To follow all these "strands" is a collective task as ambitious and incomprehensible as the will for universality of the authors that Calvino uses as an example for his chapter on Multiplicity in "Six Memos for the Next Millennium:"

Every minimal object is contemplated as the center of a network of relationships that the writer cannot help but follow, multiplying the details so that the descriptions and ramblings become infinite. Whatever the starting point is, the discourse broadens to encompass ever wider horizons, and if it may continue to develop in all directions it would reach the entire universe. ${ }^{19}$

\section{ENDNOTES}

1 George Steiner, Grammars of Creation (New Haven, CT: Yale University Press, 2002), 131.

2 Italo Calvino, Six Memos for the Next Millennium (London: Penguin Classics, 2016)

3 Gilbert Simondon, La Individuación a la Luz de las Nociones de Forma y de Información (Buenos Aires: La Cebra-El Cactus, 2009).

4 Steiner, Grammars of Creation, 190-191.

5 Blaise Pascal, Pensees and Other Writings (Oxford: Oxford University Press, 1995), pensee number 72

6 Steiner, Grammars of Creation, 192.

7 Steiner, Grammars of Creation, 192.

8 Architecture is non-significant and also non-apophantic. An apophantic statement is a logical proposition that can be proved false or truth. Aristotle, when he wished to give an example of those propositions which were not apophantic, that did not predicate the logically true and false, but nevertheless said something, gave as example invocation or prayer. The use these terms applied to architectural design in this paper is purposely conflictive and polemic.

9 Edgar Morin, El Método III. El Conocimiento del Conocimiento (Madrid: Catedra, 2006), 224-225. Translation by the authors.

10 John Cage, Silence: Lectures and Writings (Middleton: Wesleyan University Press, 1973)

11 Latin languages as French (that is also the language where the term was created) or Spanish, use the same world ("essai," "ensayo") referring both to a rehearsal and to an essay.

12 Gustavo Bueno, "Sobre el Concepto de 'Ensayo,'” presented at the symposium held at Universidad de Oviedo, Oviedo, Spain, September 28 to October 5, 1964, accessed September 28, 2018. http://www.filosofia.org/aut/ gbm/1964ensa.htm.

13 Steiner, Grammars of Creation, 134.

14 José Ortega y Gasset, Meditaciones del Quijote (Madrid: Ediciones Residencia de Estudiantes, 1914), 32. This definition matches perfectly with the non-apophantic character of Architecture previously explained.

15 Bueno, "Sobre el Concepto de 'Ensayo.'”

16 We specifically used the Dictionary of The Royal Academy of Spanish Language (RAE), but the definition is extremely similar in any English dictionary as the Oxford English Dictionary or Collins English Dictionary.

17 Viktor Shklovsky, Bowstring: On the Dissimilarity of the Similar (Champaign, IL: Dalkey Archive Press 2011).

18 Steiner, Grammars of Creation, 249.

19 Calvino, Six Memos for the Next Millennium. 